\title{
CHOOSING THE SUITABLE METHODE OF KNOW-HOW TRANSFER FROM UNIVERSITIES TO INDUSTRY BASED ON AHP TECHNIQUE
}

Amin Jahangirinia

School of Management and counting

ISLAMIC AZAD University

TEHRAN, IRAN

E-mail: a.jahangiri209@gmail.com

Somayeh Sahebi

School of Management and counting

ISLAMIC AZAD University

TEHRAN, IRAN

E-mail: so.sahebi.in.management@gmail.com

Zeinab Sahebi

Department of Industrial Management

Ershad-Damavand Higher Education Institute

z.sahebi.in.management@yahoo.com

\begin{abstract}
In the new modern global deplane, creating knowledge and optimum use of that counts as a critical factor between economics and social systems. Universities and research centers are most effective organizations in knowledge based economic. Present research main purpose is to finding technical knowledge transferring methods from university to industry and selecting suitable method focusing on country infrastructures, conditions and utilities. After reviewing a conceptual model for transferring of technical knowledge from university to industry is presented that its main parts includes technical knowledge transferring methods, selection methods standards and factors effective on transfer process. With a survey took from professionals creating firm by researcher for making product of technical knowledge method was identified as best method. Also, by reviewing factors effective on transferring technical knowledge process from university to industry, "industry suitable awareness of produced technical knowledge in universities", "Education", "financing technical knowledge owners to convert technical knowledge to product", "university need to transfer technical knowledge to industry" and "industry interest to using technical knowledge created in the country" identified as the most important factors and methods by expert choice software.
\end{abstract}

Keywords: Technical knowledge transfer, technical knowledge transfer methods, identifying suitable method to transfer technical knowledge, technical knowledge

\section{Introduction}

Currently, necessity for creation of a good relationship between university and industry is felt more than ever, as an efficient category for industrial and scientific developments as well as future successes of a society. Nowadays, new thinking as conceptual framework of "attracting financial resources through upgrading competitive ability" is introduced, upon which universities have changed their mission from mere research and educational activities to innovation, entrepreneurship, and provision of knowledge and technology to the society which in fact leads to obtaining highest financial resources.

Gaining success in knowledge based development of society implies universities to take effort in more research achievements to be transferred to industries and appropriate context to be provided 
for utilization of researchers' findings, and provision of settings for development of entrepreneurship upon knowledge, leading to creativity, innovation and more knowledge production. Hence, in order to achieve this goals identifying the criteria and methods of know-how transfer is the object of this study.

\section{Literature Review}

Del Campo suggests that there are two general strategies for commercialization of innovative products listing as licensing and venturing which means scholar himself produces products and accepts related risk. Though with minor differences, other methods result from these two. In another classification, Campo et al. provide three primary methods of commercialization of academic ideas: "Licensing, Corporate Partnership, and Start-up Companies".

In recent commercialization literature, there are four most used methods (or alternatives) as mentioned below:

1 Licensing (sales/ rent of knowledge);

2 Establishing the Spin-off by researcher (Company to be established by scholar in order for product to be developed from knowledge);

3 Joint investment of scholar and university in order for product to be developed from knowledge;

4 Joint investment of inventor and venture capitals.

Selection of each method implies consideration of some points titled criteria for choosing methods (or alternatives) and the most important identified criteria are:

1 Consideration to the scope of researcher (considering activity freedom of scholars);

2 Knowledge based businesses environments in the country;

3 Compatibility with university missions;

4 Supporting improvement of relationship between university and industry (Assistance in development of relationships between university and industry);

5 Regulations of intellectual in the country (Intellectual Property rules and regulations in the country).

\section{Hypotheses/Objectives}

This research is trying to answer the following questions:

1 What are existing methods (or alternatives) for transfer of knowledge from universities to industries?

2 What is the most appropriate way of technical knowledge transmission from universities to industries, considering country's current circumstances, facilities and limitations?

3 What are requirements for transfer of knowledge from universities to industries?

\section{Research Design/Methodology}

Time scope of study is year 2012 and data related to first stage of the study are extracted from literature review. Study was performed in development centers as well as technology parks and universities in Tehran. First questionnaire contains questions for paired comparison of criteria and also methods (or alternatives) in accordance with criteria.

In order to obtain experts' opinions, questionnaire were handed over to them in person and in referring to selected centers and after a time interval again they were collected from them in person, upon completion confirmation via telephone calls.

To determine validity, the questionnaire designed by faculty advisors review and its validity was 
verified.

Methods for gathering expert opinion to prioritize technology transfer from university to industry total of 34 questionnaires were distributed to the 31 usable questionnaires were collected from this number.

Data from the questionnaires were entered into a software Expert Choice 11 and then inconsistency rate of 4 questionnaires were recovered that inconsistency rate is lower than 0.1 the data from the questionnaires was the geometric mean. To calculate the geometric mean of the questions that managers and experts from the Iranian Research Organization for Science and Technology were completed 3 was the weight.

The completed questionnaire in technology parks, incubators, entrepreneurship centers and offices, universities, industry, weighing 2 , to questionnaires completed by the directors of the centers and weights 1 for data centers was completed questionnaires by experts.

\section{Data/Model Analysis}

\section{Software Output}

As seen in previous figure, there are 5 criteria and 4 alternatives for decision making about choosing the suitable method of knowledge transfer based on AHP technique. We estimate the relative weight of each criteria using software and the output is as the following.

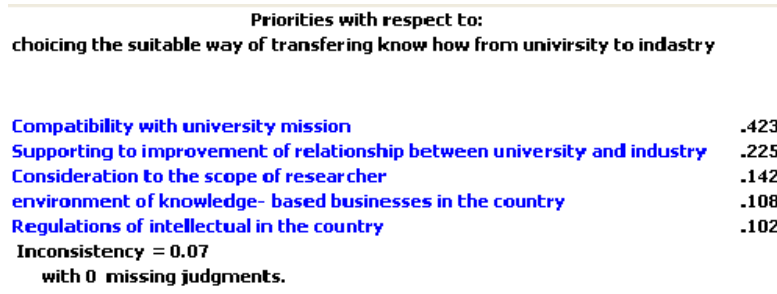

Also, we had compared the alternatives using AHP technique, here is software output of results: 


\section{Synthesis with respect to: choicing the suitable way of transfering know how from univirsity to inda}

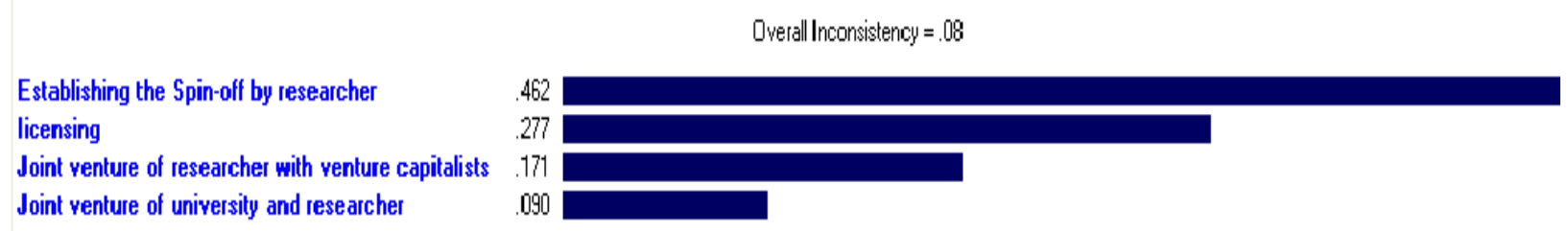

\section{Limitations}

1. Limitation in the access to the experts

2. Time limitation

\section{Conclusions}

As shown in previous sections, compatibility with university mission is the most appropriate criteria since its AHP technique score is 0.423 and after that, Supporting to improvement of relationship between university and industry criteria that has 0.225 score.

According to the results, establishment of company by scholar in order to develop product from technical knowledge is chosen as the most appropriate alternative as its acquired weight using AHP technique is 0.462 that is higher than other alternatives. Thus, in order to expedite or facilitate transfer of technical knowledge to industry, it is recommended that universities try to establish incubators and take action for their improvement and strengthening, so that necessary background would be provided for university based companies. After that alternative, licensing is the most appropriate alternative with the relative weight of 0.277 , after it comes Joint venture of researcher with venture capitalists with score of 0.171 and finally Joint venture of university and researcher with 0.09 score.

\section{Key References those 3 to 5 re}

Toole, A. A. and Czarnitzki, D., 2010, "Biomedical academic entrepreneurship through the SBIR program”, Journal of Economic Behavior \& Organization Vol.63: 716-38

Rasmussen, E., Moen, Gulbrandsen, M., 2006, "Initiatives to promote commercialization of university knowledge", Technovation Vol.26: 518-533

Zahiri, M. (2008). Presenting Map road for creating entrepreneurship center for medial unvisersities. Ph.D Thesis. Medial Science University of Iran 